\title{
Editorial
}

\section{SCIENCE AND COMPASSION}

Both these overworked words are in danger of losing their lustre and their precision. They have come to include much that is meretricious and unworthy, and not a little that may be false and misleading. In leprosy they are good words still. And they together shine forth in the pages of this and other issues of Leprosy Review.

Though science and compassion may at times have been set in stark contrast, in a sort of unyielding polarity, each needs the other if science is not to become irredeemably materialistic and if compassion is not to degenerate into sentimentalism. Science is often less than scientific, and its brave rational façade may conceal unsuspected depths of "hunches" and serendipity. And compassion-if it is to be true to its finest ideals-must take cognizance of the new knowledge if it is to use its resources aright. In the laboratory as in the field. in the pursuit of immunological understanding or the objective appraisal of a drug trial, the scientific spirit of enquiry and the compassionate spirit of service are both needed.

Over the years, of course, the proportions of the scientific and the compassionate components of the struggle against leprosy have varied within wide limits. Time was when it was rather heretical and medically impertinent even to suggest that leprosy should, or could, be regarded as a disease, to be studied like any other disease. The humanitarian movement, which was the expression of the awakening social conscience of the West, at last embraced leprosy within its purview, and the whole world is indebted to the Wellesley Baileys and the Father Damiens of a century ago and subsequently. This was compassion, disinterested compassion, of a high order. At about the same time, individual pioneers. like Hansen himself, were striving to relate their social concern to their medical knowledge, and The Mission to Lepers of India was urging the state governments to create model institutions for the care of leprosy sufferers.

Organizations that more overtly espoused the combination of compassion and science-such as the British Empire Leprosy Relief Association and the Leonard Wood Memorial, with their filials and successors-then achieved a widespread acceptance that has persisted. But with the admission of leprosy into the halls of scientific respectability, and particularly with the many significant advances now being made in immunopathology and microbiology, compassion is in danger of being squeezed out. Uneasy bedfellows at the best of times, they sometimes seem to be incompatible and mutually incomprehensible. They don't speak the same language or appeal to the same audiences. In the recent International Congress at Bergen, despite the scintillating display of brilliant scientific achievements, some participants could not suppress the suspicion that the individual patient in his tiny village "at the back of beyond" was in danger of being left out in the cold. We need the science, we desperately need more 
knowledge about leprosy-for the riddles and conundrums are still there-but we do also need the kindliness and consideration for the patient that are the hallmark of good medical practice.

It is perhaps here that the voluntary agencies can play their most useful rôle. This is certainly not to suggest either that they have a monopoly of altruistic concern or that they must eschew all suggestion of involvement in the scientific aspects of leprosy. Indeed, we may gladly pay tribute on the one hand to the deep humanitarian concern of many now engaged in leprosy research, and on the other hand to the increasing support given by voluntary agencies in such research. Complementary to the fine work of the World Health Organization and UNICEF, and the growing interest of governments, the agencies whose activities are described in this issue of Leprosy Review are not only very much alive today, but alive to the changing pattern and needs of the leprosy problem. They can supplement official programmes, and by their flexibility and initiative place significant emphasis at strategic points. They can also keep bright the ideals of altruistic service for the individual that have never been more needed than at present, and in the harsh sad world of the sufferer from leprosy. 